\title{
Effect of Metallic Particle Movement at Different Positions of Particle on Spacer in a 1- $\varnothing$ GIB
}

\author{
Giri Prasad. A, Poonam Upadhyay, M Suryakalavathi Meghana. P
}

\begin{abstract}
Gas Insulated Substation has been more credible than Air Insulated Substation thus increasing its application in the electrical industry. Though being more advantageous there are some areas in the system where there is a need for study. Metallic particle contamination is one of the areas where there are chances for the risk or failure; the particles reduce the dielectric strength of the insulating medium i.e. the SF6 gas. The metallic particles can be formed from the enclosure, conductor or the insulating material during various operations such as assembling, operating, and transporting etc. The particles can exist anywhere on the enclosure, conductor and the spacer. In this paper a single phase Gas Insulated Busduct with conductor diameter of $55 \mathrm{~mm}$ and outer enclosure of diameter $152 \mathrm{~mm}$ with a spacer inclined at an angle of 450 to the enclosure is considered. Movement of aluminum and copper particles are studied which are present on the spacer at a certain distance from the enclosure.
\end{abstract}

Index Terms-Dielectric, GIS, Metallic particle, SF6 gas.

\section{INTRODUCTION}

Gas Insulated Substation is the high voltage station with the SF6 gas as the dielectric medium having all of its parts enclosed in enclosure. In comparison with the Air Insulated Substations the Gas Insulated Substation is more advantageous in many of the aspects. The metallic particles formed during various processes in the GIB can decrease the dielectric strength of the insulating gas.

GIS at the starting stages were installed only for profit of less land requirement and the environmental advantages. Later as the technology increased the reliability of GIS raised a lot and became popular. GIS has advantages such as land cost is reduced, HV equipment can be installed, etc. All the parts are manufactured, assembled and transported to the area where the substation is to be installed. The entire parts of station are enclosed in an outer enclosure so it is protected from the outside atmosphere, salty and icy environment.

The GIS can be easily installed in the industrial and the highly populated areas and even on mountains.

SF6 has many benefits as an insulating gas. It has a greater dielectric strength, non-toxic in nature, high arc quenching property. When used in the electrical equipment it protects from fire danger, allows reducing the size and increases the

Revised Version Manuscript Received on 10 September, 2019. Giri Prasad. A, VNR VJIET (EEE), Hyderabad, Telangana, India. (Email: giridhar9ambati@gmail.com)

Dr.PoonamUpadhyay, VNR VJIET (EEE), Hyderabad, Telangana, India.(Email: poonampu@ gmail.com)

Dr M Suryakalavathi, VNR VJIET (EEE), Hyderabad, Telangana, India. Meghana.P, VNR VJIET (EEE), Hyderabad, Telangana, India.

(Email: megnamegha45@gmail.com) reliability of the system. SF6 as a good dielectric has an electron attachment property. Of the SF6 gas produced in the whole about more than $75 \%$ is used in the GIS. SF6 has also some disadvantages; it decomposes to fluoride under arc formation and produce toxic byproducts. Its dielectric strength is sensible to the non uniform fields.

Although the SF6 has advantages the existence of free metallic particles in the GIS can contribute to the reduction in the dielectric strength of the gas and also on the various properties of the support insulators. The dielectric strength of the gas is lessened by the particles formed from the conductor, enclosure and the insulator. The lower energy particle discharge affects the insulating spacer mostly when there are lastingly present on the insulator or nearer to it. When the conductor is at high field regions the particles can turn out to be a cause of chemical and electrical byproducts of SF6. If the free particles and the decomposed products of gas intrude on the spacer, depending on time and the type of particle involved the dielectric property of the insulating spacer change. The most factors guiding to the deterioration of the spacer are the humidity, physical, chemical and the contamination of the surface. The most serious threat is caused as the free moving particles gain acceleration by the increasing voltage in conductor and cause break down when they get in contact with the HV conductor.

In this work the particle movement is studied in a GIB of dimensions of diameter length $152 / 55 \mathrm{~mm}$. The metallic particles investigated for analysis are aluminum and copper which is wire shaped present on the spacer inclined at an angle of 450. A particle of length $10 \mathrm{~mm}$ is considered and of radius $(0.3 \mathrm{~mm}, 0.25 \mathrm{~mm})$.

\section{MODELING MOVEMENT OF THE METALLIC CONTAMINANT}

Though having high reliability there are chances of formation of metallic particles from the distinct operations such as transporting, assembling, operating, and circuit breaker operations. In this study the spacer is considered to be inclined to the enclosure at an angle of 450 . Various positions of the metallic particle on the spacer were considered for the study which is shown in fig. 1 . In the work a wire like particle is considered for study thus it has both friction forces acting on it due to the gas. The skin friction acting along the length of the particle and shock friction at the edges of the particle. 


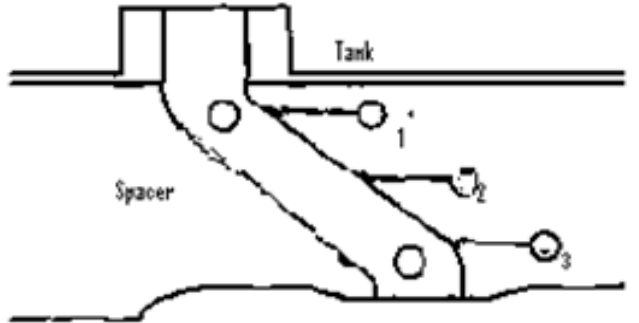

Hir Conductor

Fig. 1 Various location of particle on spacer

By considering the different forces acting on particle we get the acceleration of particle as

$$
m \frac{d^{2} y}{d t^{2}}=\mathrm{F}_{\mathrm{e}}-\mathrm{mg}-\mathrm{F}_{\mathrm{d}}
$$

' $\mathrm{y}$ ' is the vertical movement of the particle ; 'Fd' is drag force and opposes direction of motion.

Drag force - By using stoke's theorem the drag force can be formulated as

$$
\begin{gathered}
F_{d}=F_{d 1}+F_{d 2} \operatorname{Sin} \theta \\
\mathrm{F}_{\mathrm{d}}=\dot{\mathrm{y}} \pi \mathrm{r}\left(6 \mu \mathrm{K}_{\mathrm{d}}(\dot{\mathrm{y}})+2.656\left(\rho_{\mathrm{g}} \operatorname{ly} \operatorname{Sin} \theta\right)^{0.5}\right)
\end{gathered}
$$

A. Gravitational Force

$$
F g=m g \sin \theta
$$

B. Electrical Force

$$
F_{e}=\mathrm{kQ}_{\text {net }} E
$$

Fig .2 shows the various forces acting on the particle

The various forces acting on the particle are considered in eq (1) to get the movement of particle.

$$
m \frac{d^{2} y}{d t^{2}}=\mathrm{F}_{\mathrm{e}}-\mathrm{mgSin} \theta-F_{d 1}+F_{d 2} \operatorname{Sin} \theta
$$

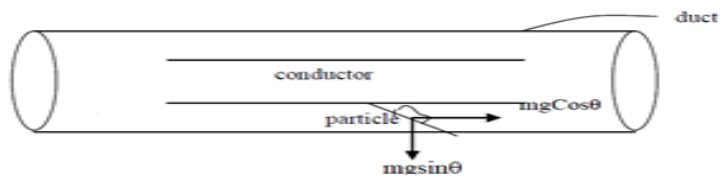

Fig .2. Different Forces acting on the particle present on spacer

By substituting various forces acting on metallic particle in the equation (6) we get equation (7) which is called as motion equation of particle.

$$
\begin{aligned}
m \ddot{y}(t)= & {\left[\frac{\pi \in_{0} 1^{2} \mathrm{E}\left(\mathrm{t}_{0}\right)}{\ln \left(\frac{2 l}{r}\right)-1} \times \frac{\mathrm{V} \operatorname{Sin} \omega t}{\left[\mathrm{r}_{0}-\mathrm{y}(\mathrm{t})\right] \ln \left(\frac{\mathrm{r}_{0}}{\mathrm{r}_{\mathrm{i}}}\right)}\right]-\pi r^{2} 1 \rho g \sin \theta } \\
& -\dot{\mathrm{y}}(\mathrm{t}) \pi \mathrm{r}\left(6 \mu \mathrm{K}_{\mathrm{d}}(\dot{\mathrm{y}})+2.656\left[\mu \rho_{\mathrm{g}} 1 \dot{\mathrm{y}}(\mathrm{t}) \operatorname{Sin} \theta\right]^{0.5}\right)
\end{aligned}
$$

By solving the above second order differential equation using RK 4th order method to get movement of particle.

\section{RESULTS AND DISCUSSIONS}

The metallic particles that are considered for the study are aluminium and copper. The particle is considered at four different distance positions from the outer enclosure which is grounded. The maximum movement of the metallic particle is calculated for different voltages.

Table 1 Radial movement of Aluminium Particle for various voltages with the particle being on spacer particle near the enclosure. $(l=10 ; r=0.25$ both in $\mathbf{~ m m})$

\begin{tabular}{|c|c|c|c|c|}
\hline S.no & $\begin{array}{c}\text { Voltage } \\
(\mathbf{k V})\end{array}$ & $\begin{array}{c}\text { Position } \\
\text { of } \\
\text { particle }\end{array}$ & $\begin{array}{c}\text { Maximum } \\
\text { Movement } \\
\text { of Particle } \\
\text { (mm) }\end{array}$ & $\begin{array}{c}\text { Change in } \\
\text { movement of } \\
\text { particle compared } \\
\text { to the before } \\
\text { position(mm) }\end{array}$ \\
\hline 1 & 120 & 0 & 30.923 & 30.922 \\
\hline 2 & 145 & 0 & 39.045 & 39.045 \\
\hline 3 & 160 & 0 & 46.091 & 46.091 \\
\hline 4 & 200 & 0 & 61.297 & 61.297 \\
\hline 5 & 245 & 0 & OF & OF \\
\hline
\end{tabular}

Table 2 Radial movement of Aluminum Particle for various voltages with the particle being on spacer at $10 \mathrm{~mm}$ distance from enclosure $(\mathrm{l}=10 ; \mathrm{r}=0.25$ both in

\begin{tabular}{|c|c|c|c|c|}
\hline S.no & $\begin{array}{c}\text { Voltage } \\
(\mathbf{k V})\end{array}$ & $\begin{array}{c}\text { Position } \\
\text { of } \\
\text { particle }\end{array}$ & $\begin{array}{c}\text { Maximum } \\
\text { Movement } \\
\text { of Particle } \\
(\mathbf{m m})\end{array}$ & $\begin{array}{c}\text { Change in } \\
\text { movement of } \\
\text { particle compared } \\
\text { to the before } \\
\text { position(mm) }\end{array}$ \\
\hline 1 & 120 & 10 & 10.261 & 0.261 \\
\hline 2 & 145 & 10 & 10.510 & 0.510 \\
\hline 3 & 160 & 10 & 10.629 & 0.629 \\
\hline 4 & 200 & 10 & 11.398 & 1.398 \\
\hline 5 & 245 & 10 & 12.634 & 2.634 \\
\hline
\end{tabular}

Table 3 Radial movement of Aluminium Particle for various voltages with the particle being on spacer at $20 \mathrm{~mm}$ distance from enclosure $(1=10 ; r=0.25$ both in mm)

\begin{tabular}{|c|c|c|c|c|}
\hline S.no & $\begin{array}{c}\text { Voltage } \\
(\mathbf{k V})\end{array}$ & $\begin{array}{c}\text { Position } \\
\text { of } \\
\text { particle }\end{array}$ & $\begin{array}{c}\text { Maximum } \\
\text { Movement } \\
\text { of Particle } \\
\text { (mm) }\end{array}$ & $\begin{array}{c}\text { Change in } \\
\text { movement of } \\
\text { particle compared } \\
\text { to the before } \\
\text { position(mm) }\end{array}$ \\
\hline 1 & 120 & 20 & 20.049 & 0.049 \\
\hline 2 & 145 & 20 & 20.765 & 0.765 \\
\hline 3 & 160 & 20 & 21.216 & 1.216 \\
\hline 4 & 200 & 20 & 22.292 & 2.292 \\
\hline 5 & 245 & 20 & 28.785 & 8.785 \\
\hline
\end{tabular}

Table 4 Radial movement of Aluminum Particle for various voltages with the particle being on spacer at $30 \mathrm{~mm}$ distance from enclosure $(\mathrm{l}=10 ; \mathrm{r}=0.25$ both in mm)

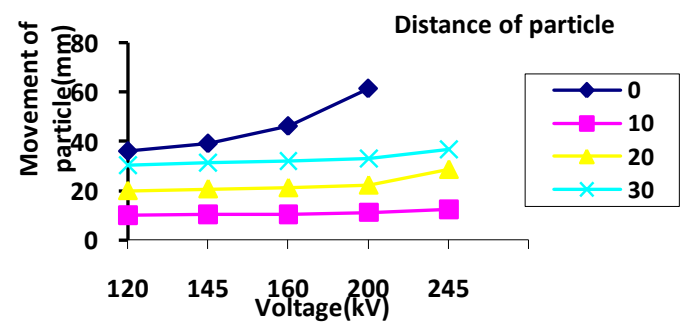

Fig 3. Comparing the radial movements of the aluminium particle at various positions of spacer for various voltages

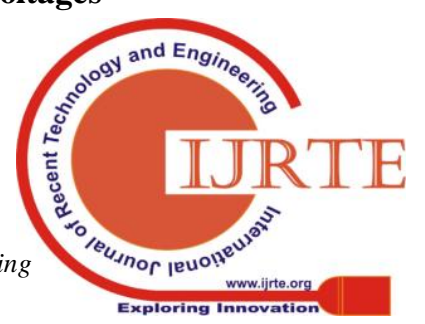


The Tables 1, 2, 3 and 4 show the movement of aluminium particle at positions $0,10,20$ and $30 \mathrm{~mm}$ distance from the enclosure.

Table 5 Radial movement of Copper Particle for various voltages with the particle being on spacer particle near the enclosure $(\mathrm{l}=10 ; \mathrm{r}=0.25$ both in $\mathbf{~ m m})$

\begin{tabular}{|c|c|c|c|c|}
\hline S.no & $\begin{array}{c}\text { Voltage } \\
(\mathbf{k V})\end{array}$ & $\begin{array}{c}\text { Positio } \\
\text { n of } \\
\text { particl } \\
\mathbf{e}\end{array}$ & $\begin{array}{c}\text { Maximum } \\
\text { Movement } \\
\text { of Particle } \\
\text { (mm) }\end{array}$ & $\begin{array}{c}\text { Change in } \\
\text { movement of } \\
\text { particle } \\
\text { compared } \\
\text { to the before } \\
\text { position(mm) }\end{array}$ \\
\hline 1 & 120 & 0 & 10.214 & 0.214 \\
\hline 2 & 145 & 0 & 10.843 & 0.843 \\
\hline 3 & 160 & 0 & 16.853 & 4.258 \\
\hline 4 & 200 & 0 & 19.793 & 9.793 \\
\hline 5 & 245 & 0 & 25.406 & 5.406 \\
\hline
\end{tabular}

Table 6 Radial movement of Copper Particle for various voltages with the particle being on spacer at $10 \mathrm{~mm}$ distance from enclosure $(l=10 ; r=0.25$ both in mm)

\begin{tabular}{|c|c|c|c|c|}
\hline S.no & $\begin{array}{c}\text { Voltage } \\
(\mathbf{k V})\end{array}$ & $\begin{array}{c}\text { Position } \\
\text { of } \\
\text { particle }\end{array}$ & $\begin{array}{c}\text { Maximum } \\
\text { Movement } \\
\text { of Particle } \\
\text { (mm) }\end{array}$ & $\begin{array}{c}\text { Change in } \\
\text { movement of } \\
\text { particle compared } \\
\text { to the before } \\
\text { position(mm) }\end{array}$ \\
\hline 1 & 120 & 10 & 10.010 & 0.010 \\
\hline 2 & 145 & 10 & 10.054 & 0.054 \\
\hline 3 & 160 & 10 & 10.189 & 0.189 \\
\hline 4 & 200 & 10 & 10.257 & 0.257 \\
\hline 5 & 245 & 10 & 10.448 & 0.448 \\
\hline
\end{tabular}

The Tables 5, 6, 7 and 8 show the movement of copper particle at positions $0,10,20$ and $30 \mathrm{~mm}$ distance from the outer enclosure.

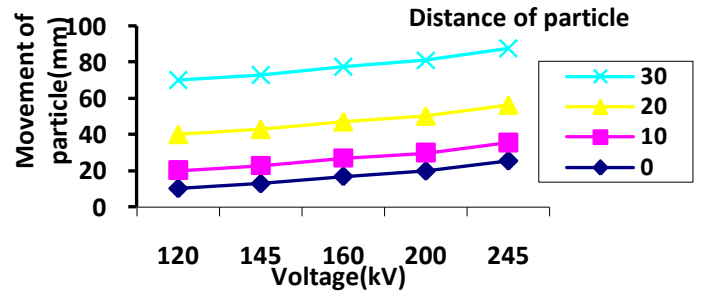

Fig 4. Comparing the radial movements of the copper particle at various positions of spacer for various voltages

Table 7 Radial movement of Copper Particle for various voltages with the particle being on spacer at $20 \mathrm{~mm}$ distance from enclosure $(l=10 ; r=0.25$ both in mm)

\begin{tabular}{|c|c|c|c|c|}
\hline S.no & $\begin{array}{c}\text { Voltage } \\
(\mathbf{k V})\end{array}$ & $\begin{array}{c}\text { Position } \\
\text { of } \\
\text { particle }\end{array}$ & $\begin{array}{c}\text { Maximum } \\
\text { Movement } \\
\text { of Particle } \\
\text { (mm) }\end{array}$ & $\begin{array}{c}\text { Change in } \\
\text { movement of } \\
\text { particle compared } \\
\text { to the before } \\
\text { position(mm) }\end{array}$ \\
\hline 1 & 120 & 20 & 20.019 & 0.019 \\
\hline 2 & 145 & 20 & 20.145 & 0.145 \\
\hline 3 & 160 & 20 & 20.206 & 0.206 \\
\hline 4 & 200 & 20 & 20.348 & 0.348 \\
\hline 5 & 245 & 20 & 20.633 & 0.633 \\
\hline
\end{tabular}

Table 8 Radial movement of Copper Particle for various voltages with the particle being on spacer at $30 \mathrm{~mm}$ distance from enclosure $(l=10 ; r=0.25$ both in mm)

\begin{tabular}{|c|c|c|c|c|}
\hline S.no & $\begin{array}{c}\text { Voltage } \\
(\mathbf{k V})\end{array}$ & $\begin{array}{c}\text { Position } \\
\text { of } \\
\text { particle }\end{array}$ & $\begin{array}{c}\text { Maximum } \\
\text { Movement } \\
\text { of Particle } \\
\text { (mm) }\end{array}$ & $\begin{array}{c}\text { Change in } \\
\text { movement of } \\
\text { particle } \\
\text { compared } \\
\text { to the before } \\
\text { position(mm) }\end{array}$ \\
\hline 1 & 120 & 30 & 30.007 & 0.007 \\
\hline 2 & 145 & 30 & 30.061 & 0.041 \\
\hline 3 & 160 & 30 & 30.282 & 0.182 \\
\hline 4 & 200 & 30 & 30.638 & 0.638 \\
\hline 5 & 245 & 30 & 31.258 & 1.058 \\
\hline
\end{tabular}

From the Fig 3 and Fig 4 show the comparison of movement of particles for various voltages present at different positions on the spacer. It is observed that the movement increments as the voltage applied increases. The movement raised as particle goes near to the $\mathrm{hV}$ conductor as it gains acceleration as the electric force increased. Being lighter in weight the aluminium particle has more movement than the copper particle.

\section{CONCLUSION}

The metallic contaminants have been considered at different locations on spacer and the movement of them is observed. It is seen that the movement of the particle increments as it reaches a position near to conductor. It is necessary to study the particle movement on the spacer as the particle presence decreases the insulation of SF6 gas

\section{REFERENCES}

1. L.G.Christophorou, J.K.Olthoff, R.J.Van Brunt, "SF6 and the Electric Power Industry", IEEE Electrical Insulation Magazine, DEIS, 1997, pp. 20-24.

2. A.H.Cookson, "Electrical breakdown for uniform fields in compressed gases", Proc. IEE, UK, Vol.117, No.1, Jan 1970, pp.269-280

3. H.Kuwahara, S.Inamura, T.Watanabe, Y.Arahata, "Effect of solid impurities on breakdown in compressed SF6 gas", IEEE trans., Vol.PAS -93, No.5, 1974, pp.1546-1555

4. H. Okubo et al., "Partial Discharge Characteristics by Metallic Particle on Solid Insulator in GIS", 13 th ISH , pp. 323-335, 2003

5. Naoki Hayakawa, et al. , "Dependence of partial discharge characteristics at spacer surface on particle size in SF6 gas insulated system", in International Conference on Condition Monitoring and Diagnosis, Beijing, China, April 21-24, 2008

6. J.R.Lahari, A.H.Qureshi, "A review of particle contaminated gas breakdown", IEEE Trans, on Electrical Insulation, Vol.EI-16, No.5, pp.388-398, 1981

7. Swarnalatha.Nattava, J.Amaranath, "Random Movement of particle trajectories in a gas insulated bus duct".

8. G.V.Nagesh Kumar et al., "Electric Field Effect on Metallic Particle Contamination in a Common Enclosure Gas Insulated Bus duct ", IEEE International Journal Dielectrics and Electrical Insulation, April 2007, pp.334-340.

9. B.Mazurek, J.D.Cross, R.G.VanHeeswijk, "The effect of a metallic particle near a spacer on flashover phenomena in SF6", IEEE Trans E1- 28, pp.219-228, 1993.

10. A.K.Chakrabarti, R.G.VanHeeswijk, K.D.Srivastava, "Spacer involvement in conducting particle initiated breakdown in compressed gas insulated systems", IEEE Trans., 1987, EI -22 (4), pp.431-438.

11. M.Eteiba, F.A.M.Rizk, N.G.Trinh, and Vincent, "Influence of conducting particle attached to an epoxy resin spacer on the breakdown voltage of compressed gas insulation", in gaseous dielectrics II, L.G.Christophorou, Pergamon press, Newyork, pp.250-254, 1980.

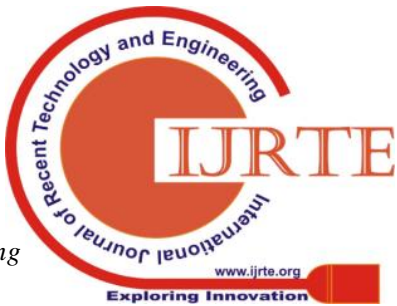

